\title{
INNOVATION AND TRAINING IN THE TEACHING OF ARCHITECTURAL PROJECTS
}

\author{
M.I. Alba Dorado \\ University of Málaga (SPAIN) \\ maribelalba@uma.es
}

\begin{abstract}
The architecture project is first of all an autonomous fact linked to a creative process. Thought and creation are intimately related in every project process and, although architecture materializes through constructive and material systems, it is only possible to conceive it through the construction of thought. For this it is necessary, on the one hand, the knowledge of guidelines, rules and objectivable principles of the architectural discipline but, on the other hand, it needs, like any creative act, to develop in a dialectical relationship with another type of material that is not specific to this discipline and is part of a personal world, the result of our experience in the world and in which the architecture project most often finds its base or owes all its wealth.

It is in this way, that the architecture project acquires values and meanings that are above the objectifiable and the tangible, thus reaching a double dimension: on the one hand, the rational and objective linked to a series of conventional knowledge, regulated and specific to the architectural discipline that evokes that character of the most technical project; and, on the other hand, the subjective and personal, common in every creative act, related to an intimate world that refers to that more subjective, unstable and unpredictable character of it. Both factors acquire the same and decisive importance in the development of the project. Likewise, they constitute two aspects equally essential for their understanding.

However, it is the most objective, rational and easily transmissible aspects that become, in most of the times, in the center of attention during the development of the project and in its teaching or in the object of study of research works, forgetting or leaving aside that highly subjective component that it possesses. In this sense, this communication aims to reflect on the teaching of the architectural project and the need to modify its usual didactic in which this factor is not taken into account with the intensity that should.

The teaching of the architecture project carried out in the current university structures, for the most part, does not contemplate the knowledge resulting from our experience in the world, from our way of seeing, feeling and being in it, focusing only on one type of conventional, regulated and objective knowledge that, at times, refers only to formalist or style aspects. Hence the need to reflect on the teaching of the architecture project so that, without forgetting those more objective and rational aspects of it, lead us to learn to work in a conscious way with those more subjective and personal.
\end{abstract}

Keywords: Teaching strategies, architectural project, innovation, teaching, learning. 